\title{
'N SKRIFTUURLIKE EVALUERING VAN ARTIKELS 72-76 VAN DIE KERKORDE VAN DIE GKSA
}

\author{
M.A. Kruger \\ Departement Nuwe Testament \& Grieks \\ HTS / PU vir CHO \\ POTCHEFSTROOM
}

\begin{abstract}
The anticles on church discipline of the Refonned Churches in South Africa (GKSA) were founded almost exclusively on Calvin's interpretation of Mathew $18.15 \mathrm{f} . \mathrm{f}$. Calvin, however, did not have manuscripts at his disposal which could enable him to do justice to the hamony of scripural evidence for church disciplinc. He used texts in Mollhen 18:15 as well as in Luke 17:3 which include the words "against you". With more mamuscripts available today this intepretation of Mouhew $18: 15$ should perhaps be reconsider'd. Furthermore, developmemt in the structural analysis of Scripture makes it necessany to re-cxamine the foundation which Calvin laid and the tradition which has bec'n built on it.
\end{abstract}

\section{INLEIDING}

Die tugartikels van die Kerkorde van die Gereformeerde Kerke in Suidelike Afrika het gegroei uit wat oorspronklik deur Calvyn in sy eerste kerkorde aanvaar is. Uit sy eksegetiese werk en sy werk aan 'n kerkorde tussen 1537 en 1541 in Geneve en Straatsburg het sy Ordonnances ecclesiastiques in 1541 tot stand gekom. In Nederland het A Lasco in Emden by Calvyn se gedagtes aangesluit. Via die sinodes van Emden 1571 en Dordrecht 1578 het die artikels na ons gekom (Bouwman, 1912:73-80 en 86-90; Kruger et al. 1966:432). Geleidelik het daar egter bykomende gedagtes gekom waarvan sommige Calvyn weerspreek op sekere punte. Dis egter veral die nuwe studie op die gebied van tekskritiek, die strukturele bestudering van Bybelboeke en die voortgaande taalstudie wat nuwe insigte gebring het waardeur ' $n$ herevaluering van hierdie artikels in die lig van die Skrif noodsaaklik geword het.

\section{ARTIKELS 72-76}

2.1 Die huidige bewoording van artikels $72-76$

Artikel 72

As iemand dan ten opsigte van die suiwerheid van die leer of vroomheid van die 
wandel sondig, moet, in sover dit heimlik is en geen openbare aanstoot gegee het nie, die reël onderhou word soos Christus duidelik in Matteus 18 voorskrywe.

\section{Artikel 73}

Die heimlike sondes waaroor die sondaar berou het nadat hy deur een persoon afsonderlik of in teenwoordigheid van twee of drie getuies vermaan is, moet nie voor die kerkraad gebring word nie.

\section{Artikel 74}

As iemand, nadat hy deur twee of drie persone in liefde oor 'n heimlike sonde vermaan is, geen gehoor gee nie of 'n openbare sonde bedryf het. moet dit by die kerkraad aanhangig gemaak word.

\section{Artikel 75}

Die versoening oor alle sondes wat uit hulle aard of deur veragting van die kerklike vermaninge openbaar geword het, moet, as daar genoegsame tekens van boetvaardigheid is, in so 'n vorm en op so 'n wyse plaasvind soos elke kerkraad dit vir die stigting van die kerk nodig oordeel. Indien daar verskil is in die kerkraad oor die vraag of die versoening in bepaalde gevalle in die openbaar moet plaasvind, moet daaroor met advies van twee naburige kerkrade beslis word.

\section{Artikel 76}

Diegene wat hardnekkig die vermaning van die kerkraad verwerp en ook diegene wat 'n openbare of ander growwe sonde gedoen het, moet van die sakramente van die Here afgehou word.

\subsection{Die probleem}

Die probleem lê opgesluit in die aanvaarding van 'n baje onsekere tekskritiese beoordeling teenoor baie duidelike Skrifgetuienis war geen teksonsekerhede is nie. Dit

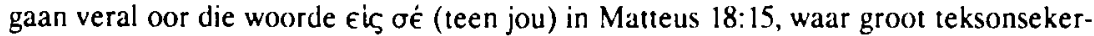
heid bestaan. Dit is onskriftuurlik om enige kerkorde-artikel, des te meer die tugartikels, te fundeer op ' $n$ teks wat tekskrities baie onseker is, terwyl daar soveel ander Skrifgetuienis is wat op ' $n$ ander weg dui. Dis ook hermeneuties nie verantwoord om voorkeur te gee aan so 'n onsekere teks met die verbygaan van onbetwisbare getuienis uit ander dele en uit die hele Skrif nie. As gevolg van die aanvaarding van hierdie woorde in sowel Matteus 18:15 as in Lukas 17:3 het Calvyn tot 'n uitleg gekom wat nie gehandhaaf kan word nie. Dit raak dio onderskeiding tussen sogenaamde sondes wat 
teen iemand persoonlik begaan is sowel as die onderskeiding tussen sogenaamde openbare en sogenaamde heimlike sondes.

\subsection{Skrifgegewens}

\subsubsection{Tekskritiese oorsig}

\subsubsection{Eksterne getuienis}

Hier word slegs aandag gegee aan die twee woorde uit Matteus 18:15 wat tans nog in hakies met 'n C-aanduiding in die United Bible Societies se derde uitgawe en deur die ses-en-twintigste uitgawe van Nestle-Aland soortgelyk aangedui word, naamlik aan $\epsilon$ is $\sigma \dot{\epsilon}$ (teen jou).

Wat die eksterne getuienis vir die woorde in Matteus 18:15 betref, is dit moeilik om op grond van die teksgetuies alleen tot 'n beslissing te kom of die woorde in die teks hoort. Grosheide (1954:282) aanvaar dat die tekslesing sonder die twee woorde die beste is. Ridderbos (1954:45) gee ook voorkeur aan die teks daarsonder.

Wat die moontlikheid betref dat die twee woorde in Lukas 17:3 ingesluit moet wees. lyk dit uiters onwaarskynlik. Dit word in UBS3 glad nie as variant vermeld nie. Ook Nestle-Aland se ses-en-twintigste uitgawe aanvaar dit nie as deel van die teks nie, hoewel dit in die tekskritiese apparaat die teksgetuies daarvoor noem.

\subsubsection{Interne getuienis}

Metzger et al. (1975:45) gebruik interne oorwegings saam met die eksterne getuienis van die manuskripte om tot 'n beslissing te kom. Hulle stel die volgende:

It is possible that the words eis $\sigma$ é arc an early interpolation into the original text, perhaps derived from $\epsilon i \bar{\epsilon} \dot{\epsilon} \mu \epsilon$ in verse 21 . On the other hand it is also possible to regard their omission as either deliberate (in order to render the passage applicable to sin in general) or accidental (for in later Greck the pronunciation of $\eta, n$ and $\epsilon 1$ was similar). In order to reflect this balance of possibilitics the Committee decided to enclose the words within square brackets.

Metzger en die Komitee gee dan die moontlikheid vir insluiting as tussen $26 \%$ en $50 \%$.

Die argumente wat aangevoer word vir weglating is miskien nie so sterk as wat hulle voorkom nie. Ten eerste is daar weinig moontlikheid dat die woorde blatant weggelaat sou gewees het om die gedeelte oor sonde in die algemeen te laat handel. Ook die 
argument dat sekere klanke eenders geklink het, staan nie sterk nie. Indien dit die geval sou gewees het, sou afskrywers en dikteerders juis in sulke gevalle dubbel seker gemaak het. Die moontlikheid dat die woorde dus deel van die oorspronklike teks kon wees, lyk dan veel geringer as tevore.

Die interne getuienis vir die uitsluiting van die frase eiç of́ (teen jou) word baie sterker as na die gedagteopbou van hierdie gedeelte uit Matteus, die ooreenstemmende gedeelte uit Lukas en die gedeelte wat waarskynlik as die bron daarvoor in die Ou Testament dien, Levitikus 19, gekyk word (vgl. Gispen, 1950:279-280).

Jesus gee in Matteus 18:15 e.v. algemene reëls vir die toekoms van die kerk. Dit is basiese, algemene reëls, wat op grond van die Woord en onder leiding van die Heilige Gees telkens weer toegepas moet word. (Dis byvoorbeeld nie verbode om in sommige gevalle iemand in die openbaar te vermaan nie, Gal. 2:11,14.) Maar hierdie algemene reëls is vir die gemeente as verbondsgemeenskap, soos die volk van die Here ook in die Ou Testament 'n verbondsgemeenskap was. Dit gaan hier nie oor die eie ego nie - dit gaan daaroor dat elkeen verantwoordelik is vir die heiligheid van die hele verbondsgemeenskap ten alle tye.

Die gedagteopbou van Matteus 18:15-35 versterk die inwendige getuienis dat die woorde $\epsilon$ Lட $\sigma \epsilon ́$ (teen jou) nie in die teks hoort nie. Wanneer hierdie gedagteopbou nagegaan word asof die woorde nie deel van die teks is nie, kry ons die volgende:

- Hoe gelowiges mekaar onderling moet vermaan, 18:15-20

- die roeping van gelowiges om medegelowiges te vermaan, 18:15a;

- die wyse waarop vermaan moet word, 18:15b-17;

- die versekering dat die Here bevestig wat hulle in gehoorsaamheid aan Hom doen, 18:18;

- as die gelowiges in hierdie saak in eenstemmigheid die leiding van die Here vra, sal hulle verhoor word omdat $\mathrm{Hy}$ by hulle is, 18:19-20.

* Hoe gelowiges mekaar onderling moet vergewe, 18:21-35

- Petrus se vraag hoeveel keer'n mens moet vergewe as daar teen jou persoonlik gesondig word, 18:21;

- Jesus se direkte antwoord - onbeperk, 18:22;

- Jesus lig sy antwoord toe deur 'n gelykenis, 18:23-34;

- Jesus pas dan die gelykenis toe, 18:35. 
Tot watter gevolgtrekking lei 'n nadere beskouing van hierdie gedeelte? Eerstens kan opgemerk word dat as die woorde éç $\sigma e ́$ (teen jou) nou hier ingesluit moes gewees het, en dit verklaar moes gewees het soos die Gereformeerde Kerke in Suidelike Afrika dit volgens hulle Kerkorde doen, naamlik dat dit net gaan oor heimlike sondes, dan beteken dit

- dat Jesus glad nie handel oor die vermaning oor openbare sondes in hierdie belangrike gedeelte waar $\mathrm{Hy}$ reëls vir die toekoms van sy kerk gee nie. Die hele konteks weerspreek so 'n gedagte.

- dat Eiç $\dot{\epsilon} \mu \epsilon$ (teen my) in 18:21 ook verklaar moet word as heimlik en nie teen iemand persoonlik nie. Dan gee die Here nou hier voorskrifte vir vergifnis van heimlike sondes, maar nie vir sondes in die openbaar nie.

- dit beteken verder dat die hele gelykenis wat dan volg ook net betrekking het op sondes heimlik gedoen. Geen persoon sal die laaste woorde van die gedeelte, (18:35) so wil toepas dat dit beteken dat ons gewaarsku word alleen oor wanneer ons ons broer nie van harte sy heimlike sondes vergewe nie. Trouens, die hele gelykenis wys dat dit gaan oor oortredinge teen iemand persoonlik wanneer hier oor vergifnis gehandel word (wat nie wil sê dat iemand nie ook persoonlik geraak word wanneer daar teen iemand anders in die verbondsgemeenskap gesondig is nie.)

\subsubsection{Skrif-met-Skrif-vergelyking}

Laat ons eerstens aandag gee aan die teks van Lukas 17:3. Daar bestaan ook manu-

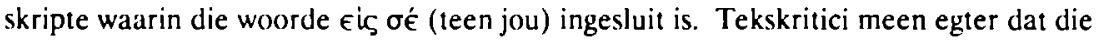
getuienis hier so swak is dat dit nie as 'n getroue lesing aanvaar kan word nie (vgl. UBS3 en Nestle-Aland-26).

Kan dit nou aanvaar word dat die $\epsilon$ ' $\sigma \epsilon \in$ (teen jou) van Lukas 17:4 terugwerkend verstaan moet word ook by 17:3? So iets is uiters onwaarskynlik. So 'n gebruik van die Griekse taal is nie bekend nie. Die teendeel is egter waar: as dit in 17:3 sou voorgekom het, sou dit kon aanvaar word ook in die volgende gedeelte al het dit nie eksplisiet daar voorgekom nie. (Contra die Deputate van die Nasionale Sinode van die Gereformeerde Kerke in Suid-Afrika en die Nasionale Sinode van die Gereformeerde Kerke 1991 wat op grond van onder andere hierdie motivering die aanbevelings van die Deputate aanvaar het; GKSA, 1991:281.) Dis nie 'n onnatuurlike oorgang as aangeneem word dat in Lukas 17:3 €iç ó (teen jou) (d.w.s. 'n sonde teen iemand persoonlik) nie veronderstel word nie, want dit gaan daar oor vermaning wat 'n 
verbondsverpligting is. Dis egter allesins onnatuurlik om terugwerkend die $\epsilon$ is $\sigma \dot{\epsilon}$ van die volgende vers daarop te laat terugslaan, veral waar vanaf vermaning na vergifnis oorgegaan word.

'n Vergelyking van Levitikus 19:16-17, Matteus 18:15-35 en Lukas 17:3-10 gee die volgende:

Levitikus 19:3-10

Oor vergewing 19:16-17a

Oor vermaning 19:17b.

Matteus 18:15-35

Oor vermaning 18:15-20

Oor vergewing 18:21-35.

Lukas 17:3-10

Oor vermaning 17:3b

Oor vergewing 17:3c-10.

Oor die gedagteopbou van Lukas 17:3-10 moet breedvoeriger ingegaan word omdat die samehang van hierdie gedeelte nie met die eerste oogopslag duidelik is nie.

* Gelowiges moet mekaar onderling vermaan, 17:3b

* Gelowiges moet mekaar onderling vergewe, 17:3c-10

- die bevel van Jesus tot vergifnis, 17:3c;

- die wyse van vergifnis, 17:4;

- die versugting van die dissipels oor die swaar eis om te vergewe, 17:5;

- die Here se antwoord dat dit deur 'n ware geloof moontlik is, 17:6;

- Jesus leer sy dissipels dat hulle in gehoorsaamheid moet uitvoer wat Hy beveel omdat Hy hulle Here is, 17:7-9;

- Jesus pas self die gelykenis toe, 17:10.

Watter gevolgtrekkings kan uit hierdie Skrif-met-Skrif-vergelyking gemaak word?

- Al drie die gedeeltes het dieselfde hoofstruktuur, naamlik dat dit handel oor vermaning en vergewing.

- By Levitikus is die orde net omgekeer. 
- Daar is hoegenaamd geen aanduiding in Levitikus dat dit net oor heimlike sondes gaan nie. Trouens, die volle verbondsverantwoordelikheid word so wyd as moontlik geraak.

- By Lukas is ook geen sprake van heimlike sonde nie (tensy die tekskritici se keuse vir weglating verwerp word en indien die woorde €iç $\sigma \dot{\epsilon}$ (teen jou) dan nog teen die moontlikheid van wat hulle kan beteken, verklaar word).

- Wat die vergifnis aangaan, gaan dit oor sonde wat teen iemand ( $\epsilon$ is $\dot{\epsilon} \mu \hat{\epsilon}$ ) begaan is. (Weer eens moet gestel word dat kragtens die aard van die verbondsgemeenskap as gemeenskap, dit ook elkeen persoonlik raak as daar teen enige medebroer of -suster gesondig word.)

- Om soos die deputate (GKSA, 1991:281) te beweer dat dit in die betrokke dele gaan om drie komponente, vermaning, vergewing en sonde, is om ongelyksoortige dinge met mekaar saam te groepeer. Waaroor word anders vermaan as dit nie oor sonde is nie? Wat word vergewe as dit nie sonde is nie? Sonde is duidelik ter sprake in die strukturele opset, maar sonde kan nie as 'n afsonderlike deel van die talalstruktuur hier genoem word nie.

\section{$2.4 \quad$ Taal-moontlikheid}

Is dit moontlik dat die Griekse woorde $\epsilon$ í $\sigma \dot{\epsilon}$ (teen jou) verklaar kan word soos Calvyn sê, naamlik as in die geheim sodat jy alleen daanan weet?

'n Aantal gevalle waar Eic (teen) ook so saam met'n persoon gebruik word, kan nagegaan word:

\section{Matteus}

Matteus het net vyf gevalle waar die voorsetsel $\epsilon$ is (teen) saam met die akkusatief van die persoon gebruik word: 18:6, waar dit soos év gebruik word (glo in My); 18:15 en 21; 26:10 waar dit met aan vertaal kan word (of $o p$ ); en 27:30 waar dit met op vertaal moet word. Dis duidelik dat as die twee gevalle in Matteus 18:15 en 21 buite rekening gelaat word, daar geen sprake kan wees van 'n betekenis van in die geheim nie.

\section{Ander voorbeelde}

In Lukas 15:18, 21 word gesê dat die seun teen die hemel (God) gesondig het. In 1 Korintiërs 8:12 word op dieselfde wyse ook gepraat van sonde teen die broers en teen Christus. In Markus 3:29 is sprake van sonde teen die Heilige Gees en net so in Lukas 
12:10. Na Lukas 17:4 is reeds verwys. In Johannes 15:21 word dit gebruik vir aan julle

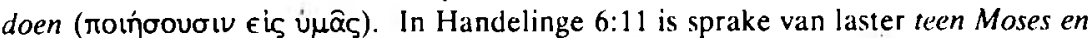

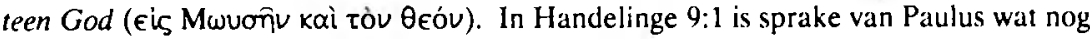

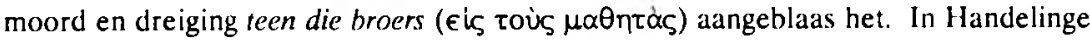

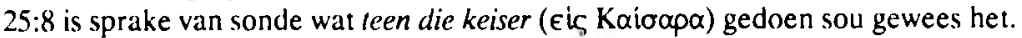

Dis duidelik uit al hierdie dele dat die verklaring van teen jou, teen my, in Matteus 18:15 en 21 met die betekenis van in die geheim waar net ek en iemand daarvan weet onhoudbaar is. Al sou die twee woorde in Matteus 18:15 voorgekom het, kon dit dus nog nie verklaar gewees het as in die geheim nie.

Die vraag waarom Calvyn, wat tog 'n uitnemende kenner van Grieks was, dan so 'n verklaring aanvaar het, kan met groot waarskynlikheid verklaar word. Hy het nie soveel teksgetuies gehad as ons nie. In die teks wat hy gehad het, was die woorde ingesluit in sowel Matteus $18: 15$ as Lukas 17:3. Hy moes dit dus verklaar. In die gewone betekenis van teen iemand persoonlik kon hy dit egter nie aanvaar nie. Daarvoor het hy die Skrif te goed geken. So 'n skielike egoistiese en individualistiese trek stry teen die hele verbondsaard en die gedagte van gemeenskap binne die gemeente. Daarom is hy baie duidelik in sy afwysing van hierdie sonde as ' $n$ sonde teen iemand persoonlik. Hy sè: "This expression, as is evident from what we have said, does not denote an injury committed against any one, but distinguishes between secret and open sins" (vertaling van Pringle - Calvyn, 1956:353). Hierdie interpretasie van Calvyn dat dit nie oor sonde teen iemand persoonlik gaan nie, word deur die genoemde Deputate verwerp (GKSA, 1991:281). Ook die sinode van 1991 aanvaar die aanbeveling wat mede op grond van hierdie opvatting gemaak is.

\subsection{Heimlike sonde of sonde teen 'n persoon?}

Dit blyk dat die Gereformeerde Kerke in Suid-Afrika in groot verwarring is omdat daar geskipper word tussen die element van persoonlike veronregting en die element dat dit gaan oor heimlike sondes.

Artikel 72 van die Kerkorde se skopus is duidelik nie dat 'n sonde teen iemand persoonlik alleen en in die geheim op die genoemde wyse gehanteer moet word nie. Die artikel moet geinterpreteer word as die wyse warop enige heimlike sonde behandel moet word. Wanneer die persoonlike element bygebring word, word dadelik toegegee dat daar nie meer sprake van heimlik is in die betekenis van fiร oé (teen jou) nie, want dan beteken $\epsilon i \zeta$ $\sigma \dot{\epsilon}$ teen jou persoonlik (ingesluit natuurlik dat dit ook teen jou is as dit teen iemand anders in die verbondsverhouding is). Dis 'n teken van hierdie verwarring dat waar die Kerkorde alleen die aspék van heimlik sondig in sy skopus het, die 
genoemde Deputate tot die konklusie kom (GKSA, 1991:281) dat Matteus 18:15 en Lukas 17:3,4 net oor persoonlike veronregting gaan.

Els ó́ (teen jou) kan nooit heimlik beteken nie, en nog minder op dieselfde plek heimlik én teen iemand persoonlik.

\subsection{Heimlike sondes en geheime vermaning}

Die opdrag tot vermaning in die geheim is baie duidelik in Matteus 18:15. Dat dit ook juis moet handel oor 'n heimlike sonde, kan net afgelei word uit 'n verkeerde verklaring van fíc $\sigma \dot{\epsilon}$ (teen jou) in dieselfde vers. Die feit dat Calvyn egter gekies het om dit as heimlike sonde te verstaan, kon ook ten dele ingegee gewees het deur die feit dat die vermaning in die geheim moet wees. Op soortgelyke wyse maak talle teoloë die fout om oor 1 Timoteus 5:20 te beweer dat die betrokke ouderlinge daar in die openbaar gesondig het (Visser, 1982:494-495). Dis 'n blote veronderstelling omdat die vermaning nou in die openbaar voor die ander ouderlinge is. Dis egter veel beter om te aanvaar dat die liefdevolle weg van Matteus 18:15 eers gevolg is en dat by volharding in die bepaalde sonde hulle dan voor die ander bestraf moet word. (ápaprávovtac - aanhou sondig is 'n praesens partisipium wat volharding of voortgang aandui en nie 'n aoristos partisipium wat 'n eenmalige sonde aandui nie.) Moet ons aanneem dat dit hier gaan oor mense wat volhardend in die openbaar sondig? Dis beter om te aanvaar dat die sonde heimlik was (of by uitsondering dalk volhardend in die openbaar). Die punt hier is dat die tug met liefde en lankmoedigheid, maar ook met beslistheid moet voortgaan.

Wat Spoelstra (1989:398) noem die oorgang van heimlike na openbare sonde, is hier op die spel. 'n Persoon wat in die geheim vermaan is en nie gehoor wou gee nie, word dan verder onder tug geplaas deurdat sy sonde nou in die openbaar genoem word. Dis hier 'n geval van progressie in die tug wat met liefde en lankmoedigheid in proses is, en nie 'n geval van 'n tand vir 'n tand nie - jy het in die openbaar gesondig, nou gaan ons jou in die openbaar vermaan (of verneder). In die vermaning (en miskien dan die sonde) wat nou openbaar word, lê die voortgang in tug. Die Skrif is ook duidelik dat hierdie voortgang in die tug sal dien tot afskrikking van ander deurdat kai (ook) gebruik word in die doelsin wat met iva kai (sodat ook) ingelui word. Hier is 'n duidelike riglyn vir die uitoefening van artikel 81 Kerkorde.

Vermaning in die geheim is nie net in ooreenstemming met die opdrag van Matteus 18:15 nie, maar lê ook in die gees van Levitikus 19:16-17 waar die beginsel duidelik is dat 'n sondaar nie net vermaan moet word nie, maar ook beskerm moet word. Die vraag kom op of dit in die gees van die Skrif is dat in die geval van 'n openbare sonde 
hierdie beginsel eenvoudig oorboord gegooi moet word. Is daar nie 'n beter pad waarop meer liefde aan die sondaar bewys kan word en hy op 'n meer liefdevolle weg in staat gestel kan word om van sy sonde af te sien of dit te bely nie? Dit gee hom die geleentheid om sy sonde, wat miskien onbewus begaan is, reg te stel sonder dat hy deur 'n verbygaan van homself nou aangekla en dus verder verneder word. Hierdie liefdesoptrede is so duidelik in ooreenstemming met die liefdesgebod dat daaroor geen betoog nodig is nie.

Maar maak die Skrif werklik onderskeid tussen die optrede by heimlike sondes en openbare sondes? As betoog word dat dit in Matteus 18:15-17 gaan om optrede teen heimlike sonde, watter optrede moet dan gevolg word vir 'n openbare sonde? In werklikheid volg die Gereformeerde Kerke dan nog presies dieselfde stappe van tug behalwe die eerste liefdestap, dit wil sê om eers persoonlik en onder vier oë te vermaan. Die betrokke Deputate beweer nadat hulle bevind het dat Matteus 18:15 en Lukas 17:3,4 net handel oor persoonlike veronregting: "Dit word ook duidelik dat Matt 18:15 (ook vers 21) en Luk 17:3-4 nie bedoel om voor te skryf hoe ons teenoor medegelowiges moet optree wat in die openbaar sondig nie. Daaroor handel die Skrif op ander plekke" (GKSA, 1991:281). Maar dis eienaardig dat in Matteus 18:15 dan slegs die persoonlike vermaning nie van toepassing gemaak word op openbare sondes nie, maar die verdere verloop van die tughandeling oor openbare sondes volg presies die pad wat Matteus hier voorskryf. Dit kom neer op willekeurige gebruik van die Skrif. Ook die voorbeeld van tug oor kerkbesoek, wat tog seker in terme van diegene wat onderskei tussen openbare en heimlike sondes 'n openbare sonde is, word die tugprosedure dan gevolg wat in Matteus 18:15-17 geleer word.

Waar is die ander plekke waarna verwys word? Ons het reeds gehandel oor 1 Timoteus 5:20. Skrywer is nie bewus van 'n ander modus operandi as dié van Matteus 18:1517 wat voorgeskryf word vir openbare sondes in die Nuwe Testament nie. Galasiërs 2:14 het nie normatiewe gesag sodat dit tot reël verhef kan word nie, maar Matteus 18:15-17 is wel so 'n algemene reël.

Die onnatuurlikheid van skeiding tussen openbare en heimlike sondes blyk verder uit die volgende. Spoelstra (1989:393) vra of die sonde of die vermaning heimlik is. Hy sê verder:

Calvyn het verborge (heimlike) sondes van openbare sondes op grond van die woorde teen jou sondig in Matteus 18:15 onderskei (Inst. IV. 12. iii). Gevolglik is al probeer om heimlike sondes teenoor die wat openbaar sou wees, te lys (Van der Linde, 1983:233, 237). Hicrdie onderskeiding word egter belwyfel.

Die woorde teen jou sondig, staan tekskrit ies nie vas en moet wannecr Skrif mut Skrif vergelyk word in die lig van Lukas 17:3,4 en Levitikus 19 eenvoudig "as (jy) jou broer (sien) sondig" beteken. Skrifverklaarders sè dat die Here in Matttcus 18 die plig om jou broer te vermaan 
beklemtoon, Icrwyl jy self sondig indien jy dit versuim. Wanneer jy liefhet en vir God en jou broer omgec, sal jy vermaan en vergewe.

Hierdie siening is duidelik 'n Skriftuurlike siening.

Die onhoudbaarheid van die onderskeid tussen heimlike en openbare sondes blyk onder andere uit die volgende geval wat nogal dikwels in Gereformeerde Kerke voorkom: Iemand hoor 'n preek. Hy alleen bemerk dat daar na sy oordeel iets onskriftuurliks is. Die preek is in die openbaar. Maar is daar nou sprake van 'n openbare sonde? Moet die persoon wat dit gehoor het nou dadelik die predikant gaan aankla by die kerkraad? Die Skriftuurlike weg van die liefde eis 'n ander optrede. Hy moet met die broer gaan praat, op dié manier misverstande uit die weg ruim, en indien nodig so die geleentheid skep dat die saak op 'n versigtige manier reggestel word sodat die heiligheid van die verbondsgemeenskap en die heiligheid van die Here geëer word.

\section{$2.7 \quad$ Konklusie}

Daar kan nie met verbygaan van soveel ander Skrifgetuienis geleun word op die gebroke riet van die aanwesigheid van $\epsilon$ ĺ ó (teen jou) (Matteus 18:15) en dan nog met 'n verkeerde verklaring daarvan nie (in die geheim by jou alleen). Soms word die betekenis van die woorde reg vertolk (teen iemand persoonlik) maar dan met'n dubbelslagtige aanhang ook van die verkeerde betekenis (in die geheim by jou alleen). Om tug so toe te pas, kan niks goeds inhou vir die Gereformeerde Kerke nie. Trouens, empiries kan al vasgestel word dat daar 'n siekte heers waar daar nie meer verbondsverantwoordelikheid en Christelike moed en liefde om mekaar te vermaan, bestaan nie, of waar oortreders eenvoudig op ' $n$ liefdelose uyse verbygegaan word en aangekla word by ' $n$ kerkraad. Dis slegs lippetaal om in sodanige gevalle nog te praat van onderlinge tug, van die funksionering van die amp van die gelowige in hierdie saak en om die gemeenskap van die gelowiges te bely.

\section{3. 'N MOONTLIKE BETER FORMULERING VAN HIERDIE ARTIKELS}

Wanneer die onderskeid in die modus operandi van die tug tussen sogenaamde openbare en heimlike sondes prysgegee word en die sonde in eng persoonlike sin teen iemand nie meer beklemtoon word nie, maar sonde in die eerste plek as sonde teen God en in en teen die verbondsgemeenskap waanan die sondaar deel is, gesien word, kan die betrokke artikels moontlik soos volg geformuleer word: 
Arikel 72:

As iemand dan ten opsigte van die suiwerheid van die leer of vroomheid van die wandel sondig, moet die algemene reël om 'n medegelowige te vermaan, onderhou word soos Christus dit duidelik in Matteus: 18:15 en Lukas 17:3 voorskryf.

\section{Artikel 73}

Wanneer 'n sondaar nadat hy aanstoot gegee het, hom na die vermaning volgens die algemene reël nie wil bekeer nie, moet dit by die kerkraad aangegee word volgens Matteus 18:17.

\section{Artikel 7}

Wanneer die sondaar hom bekeer, moet die kerkraad met inagneming van die beskerming van die sondaar en die heiligheid van die gemeente en die Here, besluit of ' $n$ versoenende handeling nodig is en wat die aard daarvan moet wees.

\section{Artikel 75}

Indien daar in die kerkraad verskil is oor die wyse van 'n versoenende optrede, moet daaroor met advies van twee naburige kerkrade gehandel word.

\section{Artikel 76}

Diegene wat hardnekkig die vermaning van die kerkraad verwerp en ook dié wat 'n growwe sonde gedoen het, moet van die sakramente afgehou word.

\section{BIBLJOGRAFIE}

BOUWMAN, H. 1912. De kerkelijke tucht. Naar het gercfomeerde kerkrecht. Kampen : Kok.

CALVYN, J. 1949. The Book of Psams. (Transl. Anderson.) Grand Rapids : Eerdman.

CALVYN, J. 1956. Harmony of the Evangelists: Matthew, Mark and Luke. (Transl Pringle.) (irand Rapids : Eerdmans.

GEREFORMEERDE KERKE IN SUID-AFRIKA. 1991. Agenda. Potchefstroom : Administraticwe Buro.

GISPEN, W. H. 1950. Het boek Leviticus. Kampen : Kok

GROSHEIDE, F. W. 1954. Het heilig evangelie volgens Mattheus. Kampen : Kok.

KRUGER, L. S. ef al. 1966. Handleiding by die kerkorde van die Gereformeerde Kerk in Suid-Afrika. Potchefstroom : Pro Rege-pers beperk.

METZGER, B. M. 1975. A Textual Commentary on the Greek New Testament. New York : United Biblc Societics.

NESTLE, E. \& NESTLE, E. el al. 1979. Novum Testamentum Graece. Stuttgart : Deutsche Bibclstiftung.

RIDDERBOS, H, N. 1954. Het evangelie naar Mattheus. Kampen : Kok. 
SPOELSTRA, B. 1989. Gereformeerde Kerkreg en kerkregering. 'n Handboek by die Kerkorde. Hammanskraal : Die Hammanskraalse Teologiese Skool van die Gereformeerde Kerke in SuidAfrika.

UNITED BIBLE SOCIETIES. 1975. The Greek New Testament. New York : American Bible Societies.

VISSER, J. 1982. Die tug oor ampsdraers. 'n Kerkregtelike en kubernetiese studie. (Ongepubliseerde prociskrif (Th.D.) - PU vir CHO.) 
